\title{
Low $-\delta^{56} \mathrm{Fe}$ ferrobasalt reveals the iron cycle of the Awulale arc belt, western Tianshan (China)
}

\author{
SHUANG YAN ${ }^{1 *}$, He-CAI NiU ${ }^{1}$, FANG HUANG ${ }^{2}$ \\ ${ }^{1}$ Guangzhou Institute of Geochemistry, Chinese Academy of \\ Sciences, Guangzhou 510640, China \\ (*correspondence: yanshuang@gig.ac.cn) \\ ${ }^{2}$ School of Earth and Space Sciences, University of Science \\ and Technology of China, Hefei 230026, China
}

The subduction factory is the key organization to control the material cycle between the Earth interior and surface, and has great contribution to compositional variations of arc magmas and metallization. Arc magmas are usually characterized by high $\mathrm{H}_{2} \mathrm{O}$ contents and high oxygen fugacity [1], facilitating magnetite removal from the early-stage magmas and inhibiting later iron enrichment [2]. Hence, it is theoretically difficult to develop iron mineralization via arc magmatism. Actually, several large-scale iron deposits were explored in the Awulale arc belt, the western Tianshan (China) and closely associated with the ferrobasaltic rocks in time and space. These ferrobasaltic rocks were thought to be the parent magmatic rocks for their iron mineralization. Revealing the petrogenesis of these ferrobasaltic rocks could be of great help to decipher the iron enrichment mechanism and iron origin of these deposits.

A Late Carboniferous (314 Ma) high-Mn tholeiitic ferrobasalt was identified in the Chagangnuoer iron deposit of the Awulale arc belt. The ferrobasalt displays abnormally light $\delta^{56} \mathrm{Fe}$ compositions $\left(-0.401 \pm 0.032 \%{ }^{--}-0.165 \pm 0.059 \%\right.$ ), far lighter than basalts reported elsewhere. We proposed that the low- $\delta^{56} \mathrm{Fe}$ signature was originated from a modified subarc mantle metasomatized by Fe-carbonate melts whereby the Fe-carbonate sediments on the subducted slab might had melted due to the thermal effect of upwelling asthenosphere mantle, and then metasomatized overlying mantle wedge to generate a high-Fe-Mn low- $\delta^{56} \mathrm{Fe}$ mantle source. This model not only reveals the petrogenesis of the low- $\delta^{56} \mathrm{Fe}$ ferrobasalt and the deep origin of iron mineralization, but also provides a novel mechanism for Fe deep recycle through subduction factory. Actually, a large amount of ankerite had been found in the exhumed eclogite of the southwestern Tianshan [3], confirming that abundant Fe-carbonates had once been subducted into deep mantle.

[1] Kelley \& Cottrell (2009) Science 325, 605-607.

[2] Gibson et al. (2000) EPSL 174, 355-374.

[3] Gao et al. (2007) GCA 71, 4974-4996. 